\title{
Saúde e Segurança do Trabalhador nos cursos técnicos da área de Informática e Edificação no Brasil
}

\section{Occupational Health and Safety in technical courses in the area of Information Technology and Building in Brazil}

\author{
Madeline Silva Pereira ${ }^{1 *}$, Isabel Ribeiro do Valle Teixeira ${ }^{1}$
}

\begin{abstract}
RESUMO
Tendo como hipótese inicial que profissões com riscos ocupacionais mais diretos e perceptíveis trabalhavam mais o conteúdo de Saúde e Segurança do Trabalho (SST) nos cursos de formação de seu profissional do que as que os danos são cumulativos, ao longo do tempo, este trabalho teve como objetivo analisar e evidenciar a proporção da presença desse conteúdo nas grades e matrizes curriculares dos cursos técnicos em informática (danos indiretos) e técnicos em edificações disponíveis publicamente (danos mais diretos) e analisá-las. Esse levantamento foi realizado através de pesquisa nos sites dos Institutos Federais (IF's) e Centros Federais de Educação Profissional e Tecnológica (CEFET's) totalizando 613 campi em todo território nacional. Os dados foram separados por estados/Regiões. Há diferenças nas proporções de cursos que oferecem tais disciplinas entre as regiões. As regiões Norte/Nordeste por exemplo tem alta proporção em comparação com a Centro-Oeste ou Sudeste. Além disso, há uma proporção muito baixa ou nula nos cursos de informática em relação aos cursos de edificações em todas as regiões. Esta diferença demosntra uma falta de orientação nacional, necessidade de um conselho mais efetivo da profissão.
\end{abstract}

Palavras-chave: Grade curricular 1; Qualidade de Vida 2; Riscos ocupacionais 3;

\begin{abstract}
Having as an initial hypothesis that professions with more direct and perceptible occupational risks worked more on the content of Occupational Health and Safety in their professional training courses than those that the damages are cumulative, over time, this work had with the objective to analyze and evidence the proportion of the presence of this content in the grids and curricular matrices of the technical courses in informatics (indirect damage) and technicians in publicly available buildings (more direct damages) and to analyze them. This survey was carried out through research on the websites of the Federal Institutes and Federal Centers for Vocational and Technological Education (CEFET's) totaling 613 campuses throughout the national territory. Data were separated by states/regions. There are differences in the proportions of courses offering such subjects across regions. The North region, for example, has a high proportion compared to the Midwest or Southeast. In addition, there is a big difference between the courses: very low or null in computer courses, when compared to building courses across the country. This trend was noticed in all regions. This difference demonstrates a lack of national guidance, a need for a more effective professional advice..
\end{abstract}

Keywords: Curriculum 1; Quality of Life 2; Occupational risks 3;

\footnotetext{
${ }^{1}$ Programa de Pós-Graduação Em Educação Profissional eTecnológica. IFSULDEMINAS - campus Poços de Caldas

*E-mail: madelinesmg@gmail.com
} 


\section{INTRODUÇÃO}

Conforme estabelecido pelas diretrizes e bases da educação nacional, os currículos do ensino médio devem considerar a formação integral do aluno, adotando assim, um trabalho voltado para a construção de seu projeto de vida e seu desenvolvimento, tanto nos aspectos físicos como nos cognitivos e socioemocionais. As diretrizes e bases preveem ainda que o Estado deve garantir uma educação escolar pública que possibilite um atendimento ao educando da educação básica por meio de programas suplementares de material didático-escolar, transporte, alimentação e assistência à saúde (BRASIL, 1996).

Essa assistência passa por sua promoção, que é o processo de capacitar a comunidade para atuar na melhoria de sua qualidade de vida e saúde, e deve ser vista como um recurso para a vida, um conceito positivo que enfatiza os recursos sociais e pessoais. A promoção da saúde transpõe um estilo de vida saudável na direção de um bem-estar global (CANADÁ, 1986).

Quando trazida no ambiente de uma escola profissional e tecnológica, ela encontra ampla relação com a promoção da saúde ocupacional dos alunos e futuros profissionais, uma vez que a morbidade geral da população ativa está relacionada com o trabalho, segundo a Declaração Sobre a Saúde dos Trabalhadores (WHO, 2006). De acordo com o documento, os avanços da tecnologia e melhorias nas ferramentas de comunicação levaram a desenvolvimentos positivos. No entanto, novos padrões de emprego e condições de trabalho em crescente expansão representam um desafio à proteção e promoção da saúde e segurança do trabalhador (SST).

O Plano de Ação Global para Saúde dos Trabalhadores prevê tomar medidas para estabelecer e fortalecer competências institucionais e capacidade de recursos humanos para lidar com as necessidades especiais de saúde ocupacional, gerar evidências e traduzir essa evidência em políticas e ações. Abrange medidas de promoção e implementação do plano global de ação sobre a saúde dos trabalhadores (2008 a 2017) a nível nacional e internacional. Inclui a prevenção primária de riscos ocupacionais, condições de emprego e uma melhor resposta dos sistemas ao bem-estar laboral dos trabalhadores (SUÍÇA, 2007).

Diante da perspectiva de novos padrões e condições de trabalho em expansão, observase que o mundo tem ficado cada vez mais informatizado, e gradualmente os setores de produção que regem a sociedade estão com o seu funcionamento submisso a programas que se conectam entre si e com os demais domínios.

Nesse sentido, é importante ressaltar que o investimento na área da tecnologia da informação está em expansão, de modo que as inovações tecnológicas chegam a constituir a 
quarta e mais atual revolução industrial em escala global. E para o setor da tecnologia da informação e comunicação, é esperado um crescimento exponencial no período compreendido entre os anos 2019 e 2021 (SCHWAB, 2016; SOFTEX, 2019).

Com isso, vislumbra-se um aumento proporcional na demanda por profissionais capacitados para atuar nesses setores. O mercado de trabalho demandará 420 mil profissionais desta área entre 2019 e 2024, o que significa 70 mil novos postos de trabalho nesse período (BRASSCOM, 2019). Desse modo, as profissões relacionadas com tecnologia da informação e comunicação têm apontado uma expectativa de crescimento promissora para os próximos anos.

Considerando esse mercado de trabalho em expansão e a necessidade de qualificação de mais profissionais dessa área, deve-se levar em conta a saúde do trabalhador como um dos fatores que está intimamente ligado a um desempenho profissional mais saudável e consequentemente a uma melhor qualidade de vida dentro e fora do trabalho.

A legislação brasileira em matéria de saúde e segurança do trabalho é relativamente nova e somente após a primeira guerra mundial em 1919, resultante de tratados internacionais, como o de Versalhes, por exemplo, algumas medidas foram consideradas, no país, visando proteger os trabalhadores uma vez que eles começavam a se concentrar nas cidades (BRASIL, 2009).

A história da saúde e segurança do trabalhador no país começou a ser traçada a partir de 1919, com a criação da Lei de Acidentes de Trabalho, a qual tornou compulsório o seguro contra o risco ocupacional. Mais tarde, em 1923, foi criada a Caixa de Aposentadorias e Pensões para os empregados das empresas rodoviárias, um marco da Previdência Social no país. Sete anos depois, a partir de 1930, foi criado o Ministério do Trabalho, Indústria e Comércio (BRASIL, 2009).

Neste sentido, em 1933, após as ações iniciais no campo da saúde do trabalhador, surgiram os Institutos de Aposentadoria e Pensões (IAP), entidades de grande porte, abrangendo os trabalhadores agrupados por ramos de atividades. No ano seguinte, teve início a Inspetoria de Higiene e Segurança do Trabalho, que passou a se chamar Departamento de Segurança e Saúde no Trabalho (DSST) em nível federal, e Superintendência Regional do Trabalho e Emprego (SRTE) em nível estadual (BRASIL, 2009).

Quase dez anos depois, em 1943, surge um importante marco na história da proteção dos trabalhadores, é criada a Consolidação das Leis do Trabalho - CLT, que regulamenta as relações de trabalho e trata da segurança e saúde do trabalhador. A consolidação das leis do trabalho passou a exigir ambientes laborais seguros e sadios, tornando obrigatória a adoção de medidas de proteção e a observância de regras para as empresas cumprirem e fazerem cumprir as normas de segurança e medicina do trabalho (BRASIL, 2009). 
Um pouco mais tarde, em 1966, ocorre a unificação dos Institutos de Aposentadoria e Pensões com a criação do Instituto Nacional de Previdência Social - INPS, atual Instituto Nacional do Seguro Social - INSS, como conhecemos hoje.

Em 1978, foram criadas as Normas Regulamentadoras Urbanas - NR's, para regulamentar os art. 154 a 201 da CLT (BRASIL, 2009).

E, em 1988, é promulgada a Constituição Federal (CF), que trata, entre vários assuntos, dos direitos dos trabalhadores urbanos e rurais e da criação das Normas Regulamentadoras Rurais - NRR. A promulgação da CF traz prevista em seu artigo $7^{\circ}$ inciso XXII a redução dos riscos inerentes ao trabalho, por meio de normas de saúde, higiene e segurança. A partir dessa, outras medidas foram criadas neste sentido, como a Lei 8213/91, que regulamentou os Planos de Benefícios da Previdência Social e incluiu os benefícios dos trabalhadores vítimas de acidentes de trabalho (BRASIL, 2009).

Entretanto, apesar dessa trajetória ao longo de algumas décadas, a evolução da SST no Brasil ocorreu de forma tardia em relação à Europa, visto que a revolução industrial brasileira começou somente por volta de 1930. E mesmo com a criação da CLT, que trouxe em seu capítulo V normas de segurança e saúde do trabalho, na década de 1970, o Brasil ainda era considerado o campeão mundial de acidentes entre os trabalhadores (BRASIL, 2009).

Adicionalmente a essa trajetória no campo da saúde ocupacional, o país faz parte de várias Convenções da Organização Internacional do Trabalho - OIT, que se tornaram, então, obrigatórias. Entre elas está a Convenção $n^{\circ}$ 155, que trata desse tema e da implantação de uma política nacional coerente em matéria de segurança e saúde dos trabalhadores e meio ambiente de trabalho (BRASIL, 2019).

Desse modo, baseado na legislação nacional vigente e acordos internacionais dos quais o Brasil faz parte, o país pertence a um grupo que está comprometido a oferecer proteção e saúde ocupacional aos seus trabalhadores. Porém, na contramão de ações efetivas de promoção da saúde e rastreamento de dados nessa área, os índices sobre saúde do trabalhador no país ainda não são claros.

De acordo com publicação do Ministério do Trabalho "os dados são ainda inconsistentes, mas acidentes e doenças do trabalho impactam diretamente na vida dos brasileiros" (BRASIL, 2018 , p. 7). A edição define adoecimento ocupacional como "qualquer alteração biológica ou funcional (física ou mental) que ocorre em uma pessoa em decorrência do trabalho" (BRASIL, 2018, p. 7). 
Sendo assim, ao avaliar o cenário atual, os avanços e as dificuldades neste quesito, percebe-se que essa é uma situação que requer atenção. E, no sentido das relações de trabalho e das mudanças pelas quais os arranjos laborais têm passado, não é uma tarefa simples promover saúde ocupacional entre a classe trabalhadora.

Com frequência, as doenças advindas da função laboral são percebidas somente em estágios mais avançados, pois, muitas vezes, em suas manifestações iniciais, os sintomas são correlatos a várias outras patologias, dificultando assim determinar um agente causal específico em certos casos. Os diversos arranjos flexíveis atuais, somados à rotatividade de um trabalhador em setores produtivos diferentes, são um obstáculo neste sentido. Adiciona-se a isso o fato de os exames admissionais nem sempre considerarem a história da atividade pregressa, o que dificulta ainda mais um processo de monitoramento em saúde do trabalhador (MINAYO-GOMEZ; THEDIM-COSTA, 1997).

Desse modo, a precarização e alta rotatividade nos postos de trabalho desfavorece uma observação de nexo causal em longo prazo na trajetória profissional do trabalhador, uma vez que ele permanece um curto período de tempo em um mesmo emprego ou função. Assim "o fato de que as qualificações são agora genéricas tem tornado mais fácil passar lateralmente de um emprego para outro, de companhia para companhia, e de setor a setor" (HUWS, 2017, p.223).

Outro complicador são as novas formas de acidentes de trabalho que atualmente fazem parte do cotidiano de quem trabalha e a implantação de programas de qualidade total e sistemas just-in-time entre outros que vinculam à lucratividade à produtividade. Fatores assim têm deixado esses empregados cada vez mais doentes levando a manifestações bastante significativas que estão relacionadas às lesões osteomusculares e transtornos mentais (ANTUNES; PRAUN, 2015).

Muitas vezes os acidentes de trabalho ou as doenças ocupacionais com manifestações físicas são mais facilmente percebidas do que os adoecimentos de ordem psíquica. Por isso, ao se falar em transtornos mentais relacionados ao trabalho (TMRT), há lacunas tanto no dimensionamento da questão, devido às subnotificações, quanto na identificação e atuação sobre os nexos causais que produzem esses eventos (ARAÚJO; PALMA; ARAÚJO, 2017).

Os profissionais de informática, dada a característica digital da sua atividade, com frequência trabalham no próprio ambiente doméstico, o que favorece o desenvolvimento de doenças ocupacionais de ordem psicológica que são menos evidentes e consequentemente menos notificadas.

Esse tipo de trabalho tem apresentado indícios de agravamento de doenças como a Síndrome de Burnout e, o fato de trabalhar remotamente não diminui o estresse causado pelo trabalho, pelo contrário, o aumenta (OLIVEIRA; TOURINHO, 2020). 
Já foi demonstrado que a era da tecnologia da informação e comunicação requer uma maior exigência cognitiva do indivíduo causando a sobrecarga nos seus processos mentais. Essa carga excessiva é causada por estímulos externos e internos e são cada vez maiores e recorrentes (PACHECO et al, 2005).

Trabalhar de casa, além de tornar o isolamento profissional mais propenso a ocorrer, faz com que as doenças e acidentes com nexo laboral fiquem também restritos ao ambiente do lar. Isso pode levar o profissional a não relacionar o ocorrido a um acidente ou doença relacionada ao trabalho.

Observa-se que, embora existam normas que tratem da proteção do trabalhador no arcabouço legal brasileiro, a prática em relação aos empregados no que diz respeito ao quesito saúde e segurança ocupacional ainda é deficitária e, no Brasil, esse assunto precisa ser discutido e associado a ações assertivas, uma vez que a realidade cotidiana por parte de quem emprega nem sempre protege quem trabalha.

Ao observar como o conteúdo de SST é trabalhado na educação profissional em outros países, verificou-se que, na França, 80\% dos currículos de ensino técnico da construção civil e $50 \%$ de cursos para prestadores de serviço tratam de segurança do trabalhador, mas, apesar de fazer parte do currículo de forma generalizada, ignoram os riscos específicos de cada profissão (BOINI; COLIN; GRZEBYK, 2017).

$\mathrm{Na}$ Suécia, os alunos de escolas técnicas apresentaram conhecimento limitado e acreditavam ser eles os responsáveis pela própria segurança. Outro dado divulgado na pesquisa foi de que os jovens são sub-representados nas estatísticas de acidentes de trabalho e concluíram que há carência de uma abordagem sistemática dos alunos sobre o ambiente de trabalho e que, o conhecimento ofertado está afastado da perspectiva legal (ANDERSSON et. al, 2014).

Nos EUA, há um conjunto de diretrizes que regem como o ensino de SST deve ser abordado nas escolas técnicas. Guerin et. al (2018) apontaram também que os estudantes possuem maior taxa de lesões graves relacionadas, comparadas com os adultos, esse é um dado importante a se considerar quando se inclui o período de estágio no trajeto de formação. Concluem, pontuando que a discussão em sala é uma ferramenta útil de participação e engajamento entre alunos com experiência de trabalho e os que ainda não trabalham e sugerem que um programa de segurança ocupacional, como ferramenta no currículo dos alunos do ensino médio, pode promover habilidades de segurança no trabalho.

Na Austrália, a educação introdutória sobre SST no ensino médio serve como um importante papel na preparação dos alunos para a entrada no mercado de trabalho (PISANIELLO, 2013). 
Ao traçar esse paralelo entre outros países e o Brasil, percebe-se que tanto aqui quanto ao redor do mundo há uma aparente necessidade de abordar o assunto nos cursos de formação de nível médio de maneira mais específica e que, quando essa prática é adotada, pode produzir resultados positivos conforme sugerido nestas pesquisas.

\section{METODOLOGIA}

A análise da abordagem sobre SST nos cursos técnicos foi feita por meio de verificação nas grades e matrizes curriculares, baseado na presença ou não de disciplinas ou conteúdos relacionadas a esse tema.

Considerando que o conceito de grade curricular é a organização de todas as disciplinas que são estudadas durante o curso e matriz curricular o documento que organiza o currículo e estipula as disciplinas obrigatórias, eletivas e a sua carga horária, levou-se em conta se o conteúdo de saúde ocupacional estava presente em pelo menos um dos dois itens.

A premissa foi que, a presença de tais disciplinas ou conteúdos na elaboração de uma matriz curricular indicava a relevância do assunto pelo núcleo estruturante do curso, como parte importante na formação do aluno.

Foram consultados 603 sites entre Institutos Federais, CEFET's e Escolas Técnicas Profissionalizantes Federais no período de março a junho de 2019, verificadas as matrizes e grades curriculares disponíveis virtualmente. Toda vez que uma disciplina de SST ou similar era identificada em um dos dois cursos das duas áreas analisadas (ligados à Informática ou Edificações) esta era contabilizada. Esses números foram organizados em tabelas e gráficos a partir do Excel e analisados via InfoStat versão 2020.

\section{RESULTADOS E DISCUSSÃO}

Dos 613 campi pesquisados, entre Institutos Federais e CEFET's, 279 ofertavam cursos técnicos na área de informática. Destas, 193 tinham a matriz ou grade curricular disponíveis nos sites, e apenas $28,19 \%$ ( $\pm 34,61)$ delas traziam o tema Saúde do Trabalhador ou conteúdo correlato (o desvio foi calculado estabelecendo-se uma média entre as regiões). Porém esta porcentagem variou muito em cada região. Na região nordeste, por exemplo, 66,12\% dos cursos apresentam este conteúdo em suas matrizes ou grades, na região Centro-Oeste nenhum dos cursos analisados ofereciam esse conteúdo ou tema correlato em suas matrizes ou grades (Tabela 1). 
Tabela 1 - Número de matrizes ou grades nos cursos de informática dos IF's e CEFET's que abordam Saúde e Segurança do Trabalho por região

\begin{tabular}{lccccc}
\hline Região & $\begin{array}{c}\text { Quantos } \\
N^{\circ} \text { de IF's } \\
\text { e CEFET's }\end{array}$ & $\begin{array}{c}\text { ofertavam } \\
\text { cursos de } \\
\text { informática }\end{array}$ & $\begin{array}{c}\text { Matrizou } \\
\text { grade } \\
\text { disponivel } \\
\text { no site }\end{array}$ & $\begin{array}{c}\text { Matrizou } \\
\text { grade que } \\
\text { abordava } \\
\text { SST }\end{array}$ & $\begin{array}{c}\text { \% de cursos } \\
\text { que } \\
\text { abordavam } \\
\text { Saúde do } \\
\text { trabalhador }\end{array}$ \\
\hline Norte & 71 & 44 & 17 & 11 & $64,7 \%$ \\
\hline Nordeste & 220 & 94 & 62 & 41 & $66,12 \%$ \\
\hline Centro Oeste & 53 & 17 & 10 & 0 & $0 \%$ \\
\hline Sudeste & 151 & 71 & 59 & 2 & $3,38 \%$ \\
\hline Sul & 118 & 53 & 45 & 3 & $6,66 \%$ \\
\hline
\end{tabular}

Fonte: Todas as matrizes publicitadas nos sites dos respectivos campus e divulgadas nos sites de cada campus foram verificadas. A verificação das matrizes foi feita de março a junho de 2019.

Para efeito de comparação, esse levantamento foi realizado nestas mesmas instituições, porém considerando a área de edificações. Dos 613 campi, 124 ofertavam cursos técnicos de nível médio nessa área. Destas, 86 tinham a matriz ou grade curricular disponíveis nos sites e, 91,34\% $( \pm 12,44)$ delas traziam o tema Saúde do Trabalhador ou conteúdo correlato. Percebeu-se que a maioria desses cursos trazia esse tema na formação do profissional. A variação entre as regiões, neste caso, é menor, porém, percebe-se que, enquanto na região norte e sul todos os cursos analisados tinham essa abordagem em algum momento, na região Centro-oeste era de apenas $70 \%$, conforme a Tabela 2.

Tabela 2 - Número de matrizes ou grades nos cursos de edificações dos IF's e CEFET's que abordam Saúde e Segurança do Trabalho por região

\begin{tabular}{|c|c|c|c|c|c|}
\hline Região & $\begin{array}{l}N^{\circ} \text { de IF's } \\
\text { e CEFET's }\end{array}$ & $\begin{array}{l}\text { Quantos } \\
\text { ofertavam } \\
\text { cursos de } \\
\text { edificações }\end{array}$ & $\begin{array}{l}\text { Matriz ou } \\
\text { grade } \\
\text { disponível } \\
\text { no site }\end{array}$ & $\begin{array}{c}\text { Matriz ou } \\
\text { grade que } \\
\text { abordava } \\
\text { SST }\end{array}$ & $\begin{array}{c}\text { \% de cursos } \\
\text { que } \\
\text { abordavam } \\
\text { Saúde do } \\
\text { trabalhador }\end{array}$ \\
\hline Norte & 71 & 19 & 10 & 10 & $100 \%$ \\
\hline Nordeste & 220 & 49 & 38 & 36 & $94,73 \%$ \\
\hline Centro Oeste & 53 & 11 & 10 & 7 & $70 \%$ \\
\hline Sudeste & 151 & 34 & 25 & 23 & $92 \%$ \\
\hline Sul & 118 & 11 & 10 & 10 & $100 \%$ \\
\hline
\end{tabular}

Fonte: Todas as matrizes publicitadas nos sites dos respectivos campus e divulgadas nos sites de cada campus foram verificadas. A verificação das matrizes foi feita de março a junho de 2019. 
Portanto, quando comparados apenas estes dois cursos parece haver uma sugestão dos dados no sentido de uma profissão que dispõe de normas de saúde e segurança específicas oferecer com maior frequência em sua formação conteúdos sobre SST. Além disso, como os acidentes e doenças ocupacionais na área da construção civil podem causar danos diretos e mais visíveis em curto prazo, há maior chance de trabalharem a promoção e prevenção dessas doenças e acidentes na formação desses profissionais. A diferença de oferta deste conteúdo, quando comparadas as proporções em cada curso por região, pode ser observada no Figura 1.

Figura 1 - Comparação da abordam da saúde e segurança do trabalho nos cursos de tecnologia da informação e de edificações por região

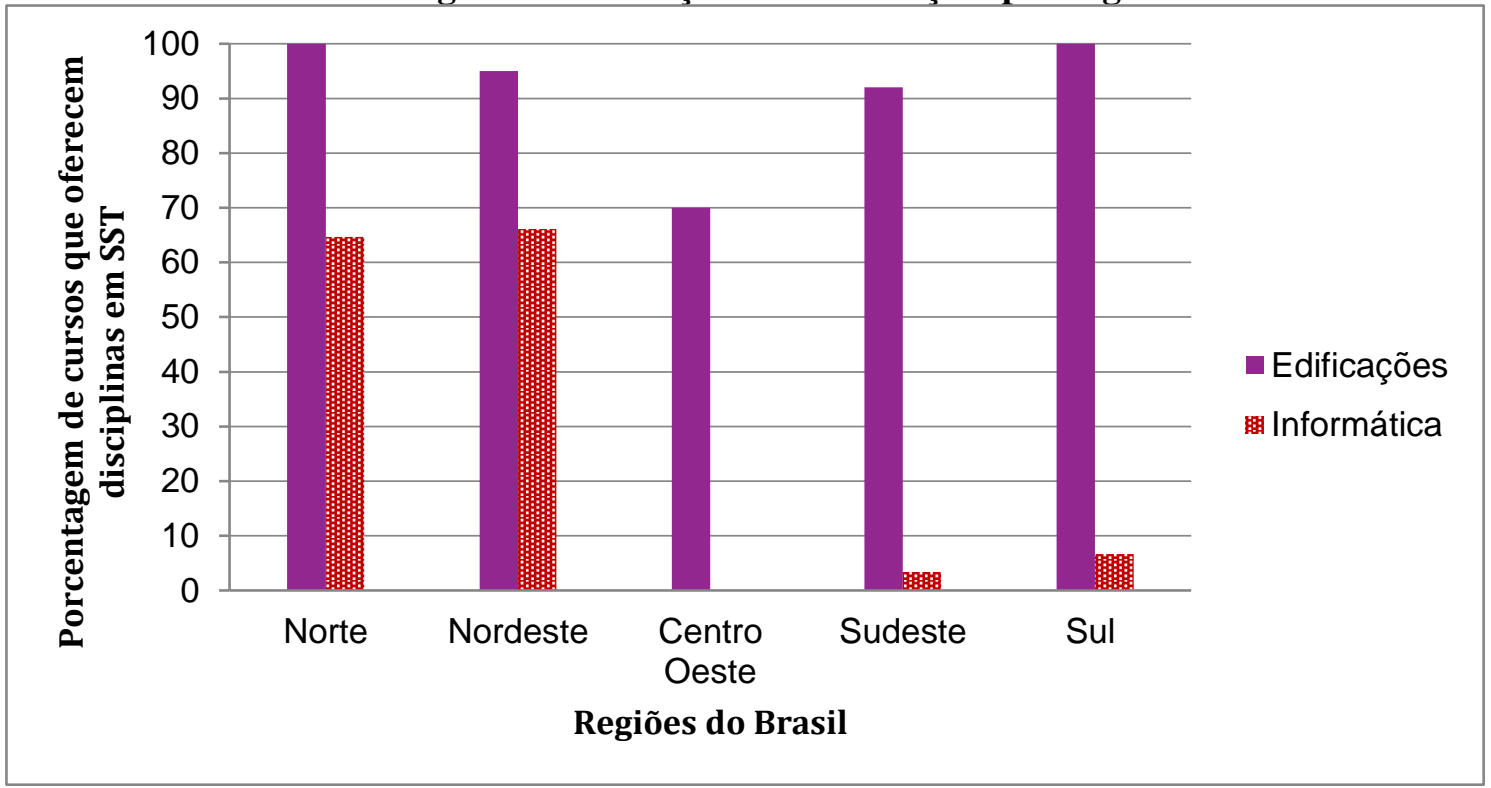

Fonte: Todas as matrizes publicitadas nos sites dos respectivos campus e divulgadas nos sites de cada campus foram verificadas. A verificação das matrizes foi feita de março a junho de 2019. $\mathrm{Na}$ comparação entre as regiões, a região Centro-Oeste apresentou diferenças estastísticas em relação às demais, demonstrando menor oferecimento de disciplinas ligadas à Saúde e Segurança do Trabalho (SST) em cursos ligados à Edificação (Kruskal-Wallis $\mathrm{p} \leq 0,05$ ). Na comparação entre os dois cursos, em todas as regiões a área Edificações apresenta maior porcentagem de disciplinas ligadas à SST (Friedman, $\mathrm{p} \leq 0,05$ ).

Observando esses dados, percebe-se que a escola, através de uma maior ou menor oferta de determinadas disciplinas, pode desempenhar um papel fundamental no processo de formação. Entretanto, espera-se que este processo seja pautado na intenção de formar sujeitos integrais, inclusive saudáveis. Fazer com o que aluno seja protagonista na construção do seu conhecimento é parte imprescindível desse trabalho que começa no ambiente escolar. 
A emancipação do sujeito, portanto, passa também pela estruturação das suas próprias ideias e, para isso, parte-se da premissa que "o processo educativo que viabiliza a construção de saberes começa na sociedade e acaba na sociedade, mas tem na escola uma mediação imprescindível" (FRIGOTTO, CIAVATA; RAMOS, 2005, p. 19-20).

Dessa maneira, ainda que existam disciplinas voltadas para saúde do trabalhador em alguns cursos técnicos em informática na rede federal, os dados da pesquisa mostraram que esse número está aquém do esperado e, outras vezes, são inexistentes em alguns lugares.

Sendo assim, essa é uma questão que continua a requerer atenção, pois cada grupo de trabalhadores pode desenvolver morbidades próprias relacionadas ao desempenho da sua atividade e “(...) não restam dúvidas de que a inserção diferenciada dos indivíduos nos processos produtivos quer no meio urbano, quer no rural, definem padrões também diversificados de morbimortalidade" (MINAYO-GOMEZ; THEDIM-COSTA, 1997, p. 24).

Portanto, ainda há margem para outros estudos no sentido de avaliar se a regulamentação profissional da área de informática pode contribuir para que sejam criadas normas de proteção à saúde e segurança desses trabalhadores voltados para essa categoria e suas especificidades e de que maneira isso pode ser viabilizado.

\section{CONSIDERAÇÕES FINAIS}

Os dados mostraram que em todo o Brasil, na rede federal onde eram ofertados cursos técnicos profissionalizantes na área de edificações e informática foi possível estabelecer uma comparação no que diz respeito à oferta de Saúde Ocupacional em suas matrizes e grades, Tal fato permitiu-nos identificar uma grande discrepância entre cursos com perfis diferentes. Um curso como os ligados à área de Tecnologia da Informação e Comunicação (TIC), em que dificilmente vai oferecer disciplinas de carater de cuidado com o trabalhador, pode resultar em profissionais com alto iíndices de queixas em saúde e baixa qualidade de vida. Além das disciplinas ligadas à este tema, seria importante que estas fossem específicas para o tipo de trabalho. Mesmo que uma regulamentação da profissão possa orientar a formação dos profissionais quanto à sua saúde e segurança. Edificações tem, TIC não tem. Uma orientação nacional via órgãos governamentais poderia suplir esta demanda. 


\section{REFERÊNCIAS}

ANTUNES, Ricardo; PRAUN, Luci. A sociedade dos Adoecimentos no Trabalho. Revista Serv. Soc. Soc., São Paulo, n. 123, p. 407-427, jul./set.2015. Disponível em: https://www.scielo.br/pdf/sssoc/n123/0101-6628-sssoc-123-0407.pdf. Acesso em: 20 mai. 2020.

ARAUJO, Tania; PALMA, Tarciso; ARAUJO, Natália. Vigilância em Saúde Mental e Trabalho no Brasil: características, dificuldades e desafios. Ciênc. saúde coletiva, Rio de Janeiro, v. 22, n. 10, p. 3235-3246, out.2017. Disponível em:

http://www.scielo.br/scielo.php?script=sci_arttext\&pid=S1413-

81232017021003235\&lng=en\&nrm=iso. Acesso em: 02 abr. 2021.

BOINI, Stephanie; COLIN, Regis; GRZEBYK, Michael. Effect of occupational safety and health education received during schooling on the incidence of workplace injuries in the first 2 years of occupational life: a prospective study. BMJ Open, London, 2017. Disponível em: https://bmjopen.bmj.com/content/7/7/e015100. Acesso em: 08 nov. 2018.

BRASIL. Decreto-lei no 5.452, de 1o de maio de 1943. Aprova a Consolidação das Leis do Trabalho. Disponível em: http://www.planalto.gov.br/ccivil_03/decretolei/del5452compilado.htm. Acesso em: 04 jun. 2020.

. Lei n 8213 de 1991. Dispõe sobre os Planos de Benefícios da Previdência Social e dá outras providências. Disponível em:

http://www.planalto.gov.br/ccivil_03/leis/l8213cons.htm. Acesso em: 10 abr. 2021.

. Lei n 9394 de 20 de dezembro de 1996. Lei de Diretrizes e Bases da Educação Nacional. Disponível em: http://www.planalto.gov.br/ccivil_03/leis/19394.htm. Acesso em: 04 mar. 2020.

Ministério da Educação; Org. TAVARES, Cláudia Régia Gomes. Curso Técnico em Segurança do Trabalho, Segurança do Trabalho I, Introdução à Segurança do Trabalho, 2009. 28 p. Disponível em:

http://redeetec.mec.gov.br/images/stories/pdf/eixo_amb_saude_seguranca/tec_seguranc a/seg_trabalho/291012_seg_trab_a01.pdf. Acesso em: 04 jun. 2020.

. Projeto de Lei da Câmara dos Deputados n 3065/2015. Dispõe sobre a regulamentação do exercício da profissão de Analista de Sistemas, Desenvolvedor, Engenheiro de Sistemas, Analista de Redes, Administrador de Banco de Dados, Suporte e suas correlatas, cria o Conselho Federal e os Conselhos Regionais de Informática e dá outras providências. Disponível em: https://www.camara.leg.br/propostaslegislativas/1738563. Acesso em: 10 mar. 2020.

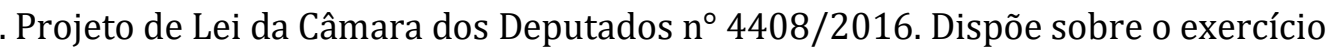
profissional na área de informática. Disponível em: https://www.camara.leg.br/propostas-legislativas/2077374. Acesso em: 20 mar. 2021.

Projeto de Lei da Câmara dos Deputados n 5101/2016. Dispõe sobre a regulamentação do exercício da profissão de Analista de Sistemas e suas correlatas. Disponível em: https://www.camara.leg.br/propostas-legislativas/2082639. Acesso em: 10 mar. 2020.

. Projeto de Lei do Senado $n^{\circ} 317 / 2017$. Dispõe sobre a regulamentação do exercício das profissões de Analista de Sistemas, Desenvolvedor, Engenheiro de Sistemas, Analista de Redes, Administrador de Banco de Dados, Suporte e suas correlatas, e dá outras 
providências. Disponível em: https://www25.senado.leg.br/web/atividade/materias//materia/130777. Acesso em: 10 mar. 2020.

Ministério do Trabalho. Cartilha Adoecimento Ocupacional: um mal invisível e silencioso. 2018. Disponível em: https://www.gov.br/trabalho/pt$\mathrm{br} /$ inspecao/escola/cartilhas-manuais-publicacoes/cartilha-adoecimento-ocupacionalum-mal-invisivel-e-silencioso.pdf/view. Acesso em: 04 mar. 2021.

. Decreto $\mathrm{n}^{\circ} 10.088$ de 2019. Consolida atos normativos editados pelo Poder Executivo Federal que dispõem sobre a promulgação de convenções e recomendações da Organização Internacional do Trabalho - OIT ratificadas pela República Federativa do Brasil. Disponível em: http://www.planalto.gov.br/ccivil_03/_Ato20192022/2019/Decreto/D10088.htm\#art6. Acesso em: 20 jun. 2020.

Ministério Público do Trabalho. Nota técnica 17/2020 do GT NACIONAL COVID 19 e do GT NANOTECNOLOGIA 2020. Nota técnica para a atuação do Ministério Público do Trabalho para a proteção da saúde e demais direitos fundamentais das trabalhadoras e trabalhadores em trabalho remoto ou home office. set.2020. Disponível em: https://www.conjur.com.br/dl/nota-tecnica1.pdf. Acesso em: 20 mar. 2021.

CANADÁ. Carta de Ottawa. In: 1aㅡ Conferência Internacional sobre Promoção da Saúde. Ottawa, 1986. Disponível em: http://bvsms.saude.gov.br/bvs/publicacoes/carta_ottawa.pdf. Acesso: 04 mar. 2020.

HUWS, Ursula. A formação do cibertariado: trabalho virtual em um mundo real. Campinas: Editora da Unicamp, 2017

MINAYO-GOMEZ, Carlos; THEDIM-COSTA, Sonia. A construção do campo da saúde do trabalhador: percurso e dilemas. Cad. Saúde Públ., Rio de Janeiro, 13 (Supl. 2):21-32, 1997. Disponível em: https://www.scielo.br/pdf/csp/v13s2/1361.pdf. Acesso em: 04 abr. 2020.

OLIVEIRA, Luis. TOURINHO, Luciano. Síndrome de Burnout, teletrabalho e revolução tecnológica: um estudo do adoecimento profissional em tempos de Covid-19. Revista Jurídica Trabalho e Desenvolvimento Humano. Procuradoria Regional do Trabalho da

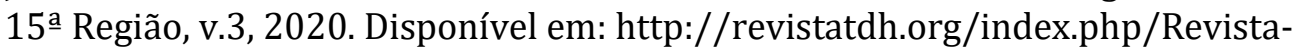
TDH/article/view/83/57. Acesso em: 20 mar. 2021.

PACHECO, Waldemar; PEREIRA JR., Casimiro; PEREIRA, Vera Lúcia Suarte do Valle; PEREIRA FILHO, Hyppólito do Valle. A era da tecnologia da informação e comunicação e a saúde do trabalhador. Revista Brasileira de Medicina do Trabalho, Belo Horizonte. v. 3, n. 2, p. 114-22, ago./dez.2005. Disponível em: http://www.rbmt.org.br/details/156/ptBR/a-era-da-tecnologia-da-informacao-e-comunicacao-e-a-saude-do-trabalhador Acesso em: 15 abr. 2021

PISANIELLO, Dino L.; STEWART, Sasha K.; JAHAN, Nasreen; PISANIELLO, Sandra L.; WINEFIELD, Helen; BRAUNACK-MAYERA, Annette. The role of high schools in introductory occupational safety education - Teacher perspectives on effectiveness. Safety Science, Amsterdam, v. 55, p.53-61, 2013. Disponível em: http://doi.org/10.1016/j.ssci.2012.12.011. Acesso em: 08 nov. 2018.

WORLD HEALTH ORGANIZATION. (WHO). Declaration on Workers Health. Approved at the Seventh Meeting of the WHO Collaborating Centres for Occupational Health, Stresa, Italy, 8-9 June 2006. Disponível em: https://www.who.int/occupational_health/Declarwh.pdf?ua=1. Acesso em: 04 mar. 2020. 
SUÍÇA. Plano de Ação Global para a Saúde dos Trabalhadores. In: 60ª Assembleia Mundial da Saúde da OMS Genebra, 23 de maio 2007. Disponível em:

https://www.who.int/occupational_health/WHO_health_assembly_en_web.pdf?ua=1.

Acesso em: 04 mar. 2020.

SCHWAB, Klaus. A Quarta Revolução Industrial. Editora Edipro, 2016.

SOFTEX. Tendências na transformação digital e os novos players nas organizações: do CIO ao CDO, 2019. Disponível em: https://softex.br/download/tendencias-natransformacao-digital-e-os-novos-players-nas-organizacoes-do-cio-ao-cdo/ Acesso em: 04 mar. 2020

Recebido em: 05/01/2022

Aprovado em: 08/02/2022

Publicado em: 11/02/2022 